\title{
Awareness of sexual trafficking and associated factors among youth females in debre birhan town, north shewa, Ethiopia, 2017
}

\begin{abstract}
Background: The International Labor Organization estimated that there are 4.5 million victims of forced sexual exploitation worldwide; $98 \%$ of whom are estimated to be women and girls due to low awareness of sexual trafficking. In recent years, there has been a great attention of sexual trafficking in Africa in general and the sub-Saharan African region in particular as a real challenge due to low awareness about it. Youth females are the most targeted group of sexual trafficking. This study was used to assess Awareness of sexual trafficking and associated factors among youth females in Debrebirhan town, North Shewa, Ethiopia, 2017.
\end{abstract}

Methods: Community based cross-sectional study was conducted. The participants in the study were selected using systematic random sampling techniques. A structured Amharic version questionnaire was used to collect data. Data were entered, cleaned and analyzed using SPSS 22. Logistic regression analysis was used to identify factors associated with sex trafficking awareness. The study findings were displayed by using texts, tables and figures.

Result: In this study, a total of 582 respondents were included. About $300(52 \%)$ of respondents reported that they had awareness about sexual trafficking. Mother's education status (elementary\& secondary) $[\mathrm{AOR}=2.068,95 \% \mathrm{CI}(1.079-3.963)]$ and $[\mathrm{AOR}=3.446$, 95\% CI(1.298-9.154)],parents' occupation (Gov'tal employee)[AOR=2.2, 95\%CI(1.024.747)], Youth females' occupation(gov'tal work)[AOR $=6.203,95 \% \quad$ CI(1.09935.005)], having television at home $[\mathrm{AOR}=2.083,95 \% \mathrm{CI}(1.305-3.326)]$ and taking training on gender issues $[\mathrm{AOR}=3.887,95 \% \mathrm{CI}$ : $(2.591-5.832)]$ were the possible independent risk factors for awareness of sexual trafficking.

Conclusion: In this study, sexual trafficking awareness was low among youth females. Mother education status, parents' occupation, current jobs of participant, having television in home and have taking training on gender issues were significantly associated with awareness of sexual trafficking. Therefore, providing education about sexual trafficking will help to increase sexual trafficking awareness among youth females.

Keywords: sexual trafficking, associated factor, youth female, harboring, deception, violence, poverty, unemployment, vulnerability, smuggled
Volume 8 Issue 5 - 2019

\author{
Ayele Mamo Abebe,' Fikir Alebachew \\ Mengistu, ${ }^{2}$ Mesfin Wudu Kassaw, ${ }^{3}$ Mulugeta \\ Mihrete Tefera ${ }^{4}$ \\ 'Department of nursing, Debre Birhan health science college, \\ Amhara, Ethiopia \\ ${ }^{2}$ Department of nursing, Dessie health sciences college, Amhara, \\ Ethiopia \\ ${ }^{3}$ Department of nursing, College of health sciences, Woldia \\ University, Amhara, Ethiopia \\ ${ }^{4}$ Pharmacy Department, Bahir Dar health science college, \\ Ethiopia
}

Correspondence: Ayele Mamo Abebe, Department of Nursing, Debre Birhan Health Sciences College, Debre Birhan 37,Amhara, Ethiopia, Email ayelemamo12@gmail.com

Received: August 10, 2019| Published: September 27, 2019
Abbreviations: AIM, action and investment to defeat malaria; $\mathrm{CDC}$, center for disease control; FGD, focus group discussion; HC, health center; HEP, health extension program; HP, health post; HSB, health seeking behavior; $\mathrm{HH}$, household; IEC, information education communication; IMNCI, integrated management of neonatal and childhood illness; $\mathrm{MOH}$, ministry of health; NMV, non-mobile clinic village; MV, mobile clinic villages; PHC, primary health care; RDT, rapid diagnostic tests; SSA, sub sahara Africa; TM, traditional medicine; WHO, world health organization

\section{Introduction}

The United Nation defines sex trafficking as "the recruitment, transportation, transfer, harboring, or receipt of persons, by means of the threat or use of force or other forms of coercion, of abduction, of fraud, of deception, of the abuse of power or of a position of vulnerability" for the purposes of sexual exploitation and for economic and other personal gains. ${ }^{1}$ Sexual trafficking is not synonymous with prostitution but it is an umbrella term that may include commercial sex work such as prostitution, but also pornography, exotic dancing, stripping, live sex shows, mail-order brides, military prostitution, and sexual tourism. ${ }^{2}$ According to the United Nations Office of Drugs and Crime worldwide report, most migrant women and girls have no awareness about sexual trafficking. ${ }^{3}$ According to the United Nation Office on Drugs and Crime(UNODC) report, the numbers of trafficked women have increased both in developed and developing countries. ${ }^{4}$ It is difficult to estimate accurately the global prevalence of sexual trafficking due to its hidden nature. ${ }^{5}$ But a recent estimate indicated that trafficking reaches between one and two million people each year worldwide; $60-70 \%$ of which are young girls. ${ }^{6}$ The International Labor Organization (ILO) estimated that there are 4.5 million victims of forced sexual exploitation worldwide; $98 \%$ of whom are estimated to be women and girls. ${ }^{7}$ According to the ILO report the related causes of unawareness of sexual trafficking are its hidden nature, Access of source of information, socio-demographic condition of the families and the participant, training on gender based violence, poverty, unemployment and political conditions. 
Sexual trafficking in Ethiopia, mostly takes the form of transporting migrants by fraud, deception and different forms of coercion and it causes a number of serious problems, turning the hope of many young girls to tragedy. ${ }^{8}$ As explained by UNODC in the above, Most of Ethiopian women and young girls migrant do not have awareness about sexual trafficking. ${ }^{4}$ According to a survey report by UNICEF, sexual trafficking is considered as either severe or very severe problem in more than $70 \%$ of West and Central African counties; it is identified as so in $33 \%$ of the East and Southern African counties. ${ }^{9}$ According to U.S. Department of State report, in the first half of 2012 alone, over 160,000 migrants migrated regularly to Saudi Arabia to work in the domestic sector, using the services of Private Employment Agencies (PEAs). ${ }^{10,11}$ ILO estimates that irregular Ethiopian migration to Saudi Arabia is double the size of regular migration. ${ }^{12}$ The US Department of State reports that Ministry of Labor and Social Affairs (MOLSA) even estimates that the 200,000 regular labour migrants in 2012 represent just 30 to $40 \%$ of all Ethiopians migrating to the Middle East, implicating that the remaining $60 \%$ to $70 \%$ are either sexually trafficked or smuggled with the facilitation of illegal brokers. ${ }^{13}$ The above report also shows that of the migrants of the year 2012, more than $85 \%$ are youth female students who either dropped or quitted schools at primary or secondary level. Similarly, the ILO report of 2013 on migrant workers indicated that, one of the largest current international migration flows is Ethiopian women and girls migrating to the Middle East as domestic workers, which also often occurs through trafficking. In recent times the number of sexually trafficked Ethiopian women to the Middle East has dramatically increased. ${ }^{14}$ Because the migrants do not have awareness about the sexual trafficking and they do not know what they will do in the foreign countries after they arrive. ${ }^{4}$

The studies conducted in Bahir Dar city in 2014 and in 2015 in Nepal showed that $60 \%$ and $76 \%$ of the respondents had awareness of sexual trafficking respectively. ${ }^{15,16}$ According the Nepal's study, relatives and friends were mentioned as mediators for sexual trafficking by $51.4 \%$ and $34.2 \%$ of the respondents respectively whereas in Bahir Dar study Friends and brokers were mentioned as mediators for sexual trafficking by $87 \%$ and $74 \%$ of the study participants respectively. ${ }^{16,15}$ The above findings are consistent with the studies done in Nigeria and South Africa. ${ }^{17-19}$ Based on the study done in Nepal,62.2\%, $58.6 \%, 56.8 \%$, and $25.2 \%$ of the respondents mentioned poverty, lack of awareness, interest on big money, and illiteracy respectively as reasons for being trafficked. ${ }^{16}$ Similarly the study done in Bahir Dar city, $45 \%, 50 \%$ and $72 \%$ of the study participants mentioned poverty, unemployment and hoping for a better life elsewhere respectively as reasons for sex trafficking. ${ }^{15}$ These findings are consistent with those reported in studies in South Asia, Nigeria, and South Africa. ${ }^{17,20,21} \mathrm{~A}$ Cross-Sectional Study carried out in Nepal revealed that $58.6 \%$ and $25.2 \%$ of the respondents mentioned lack of awareness and illiteracy respectively as associated for being trafficked. ${ }^{16}$ Correspondingly, the studies done in Nigeria and Ethiopia (Bahir Dar) had shown 56.1\% and $18 \%$ of the participants reported illiteracy as factors associated with sex trafficking respectively. ${ }^{18,15}$

The consequence of sexual trafficking is multifold including the physical, psychological, social, economic and political problems. Different studies also reported that sex trafficking has high negative impact on the physical, mental, social and psychological wellbeing of women and girls. ${ }^{10,22-25}$ Sexually-trafficked women and girls are more likely to contract HIV/AIDS and other STDs. ${ }^{26}$ Infectious diseases such as tuberculosis are also a frequent consequence for trafficking victims. ${ }^{27}$ When intervention efforts are concerned, Ethiopian government and non-government al organizations are tried to protect the human right of sexual trafficked women in Ethiopia and out of the Ethiopia. Despite efforts made by the government and nongovernmental organizations, victims of sex trafficking are increasing. Still, many women and young girls want to go abroad without knowing the situations there. ${ }^{4,28}$ There are also some studies conducted by individual researchers on human trafficking in Ethiopia, ${ }^{29-33}$ Most of these studies are highly concerned on the investigation of the challenges, prospects, and different kinds of right violations that Ethiopian domestic workers experience in the Arab Middle East. However, during this time, there is no enough research on youth females' awareness about sex trafficking in the study area as well as in Ethiopia. So, reliable evidence on awareness of sex trafficking at grass root level is important to formulate evidence based approaches for effective preventative interventions against sexual trafficking. Therefore, this study is designed to assess awareness of sex trafficking and associated factors among youth females in Debre Birhan town, North-Shewa, Ethiopia

\section{Methods and materials}

\section{a. Study area and period}

The A community based cross-sectional study design was conducted in Debre Birhan town, the capital city of North Shewa, which is located $120 \mathrm{kms}$ North of Addis Ababa, Ethiopia. According to Debre Birhan town administrative office report of 2009 E.C population census, the total population of the town was estimated 97969(44,300 males and 53,669 females). There were 14437 youth girls in Debre Birhan town. The study period was from February 7 to April 7, 2017. The source population was all youth females aged 15-24years who were living in the Debre Birhan town.

\section{b. Eligibility criteria}

Inclusion Criteria: All youth females aged 15-24years who were living in the selected kebeles at least for six Months.

Exclusion criteria: Youth female girls who were mentally ill, chronically ill who could not reply interview and have hearing problem.

\section{c. Sample size determination and sampling procedure}

Sample size: Single population proportional formula was used to determine sample size based on the following assumptions: $95 \%$ level of confidence $(Z \alpha / 2=1.96)$, the proportion of respondents who heard about sex trafficking in a previous study $(\mathrm{p}=60 \%),{ }^{26}$ and margin of error $(\mathrm{d}=5 \%)$. The sample size will be calculated as follow.

$$
n i=\frac{\left(Z_{a / 2}\right)^{2} P(1-P)}{d^{2}}=\frac{(1.96)^{2}(0.6)(0.4)}{(0.05)^{2}}=368.79 \sim 369
$$

The sample size was 582 by using design effect 1.5 and then $5 \%$ contingency.

\section{d. Sampling techniques}

The multi-stages sampling method was employed. The Debre Birhan town had 14kebeles. Then, by using simple random sampling technique six kebeles were selected. By using population proportion to size each Kebele had its own sample size. Household was used as a sampling unit in this study. By listing the households, I gave code for every household for those with youth female starting from North direction and goes to East, South and West direction. 
Households were selected using systematic random sampling. The sampling interval $(\mathrm{K})$ was obtained by dividing each selected kebele's total house hold number with youth female to the sample size of each selected kebele, so that $\mathrm{k}=\mathrm{N} / \mathrm{n}=$ every 7 th house hold(hh) was visited until we got 582 youth female. The first house hold was selected by lottery method from the sampling interval $(\mathrm{K})$. If there was more than one youth female in a household, lottery method was used to select one participant. If the selected youth was not available at home at the time of visit, revisit for the second time was made to contact the selected youth for interview. If I did not get again I took the reserved on from the house which had more than one girls. The data collection time was afternoon after the class for students and weekend (Saturday and Sunday) since most of the participant were students (Figure 1).

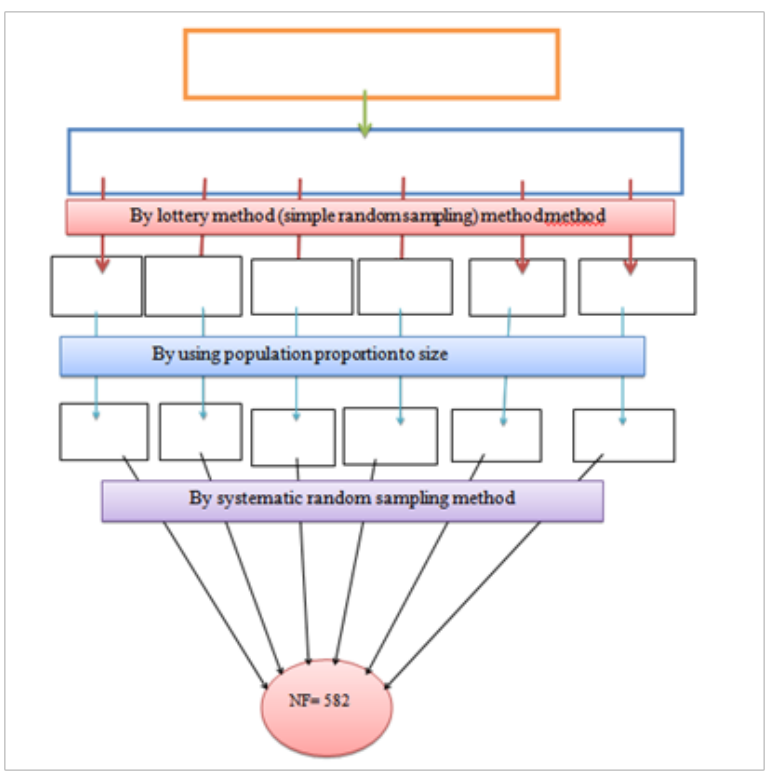

Figure I Schematic representation of sampling procedure for debrebirehan town, Ethiopia 2017.

\section{e. Data collection tool and procedure}

Structured self-administered questionnaire was used to elicit information about sexual trafficking from the study participants. The questionnaire was taken from previous similar study in Bahir Dar town. ${ }^{26}$ The English version questionnaire was translated to Amharic version questionnaire. Again the Amharic language questionnaire was back translated to English language to check for its original meaning. The questionnaires had two sections. The first section was about socio-demographic characteristics of the youth females and their parents and the second section was on sexual trafficking awareness. Five health extension workers and one BSc nurse were recruited as data collectors and supervisor for this study, respectively. The data collection time was afternoon after the class for students and weekend (Saturday and Sunday).

\section{f. Data quality control}

To assure high quality of data, training was given for data collectors and supervisors for one day and the questionnaire was pretested on $10 \%$ of youth girls from non-selected kebeles and correction was made accordingly. Continuous supervision was done at the spot both by the primary investigator and one recruited supervisor to check completeness of data and to monitor the whole data collection process. Finally before beginning the analysis, accuracy of data was verified during the time of data entering into SPSS version 22.

\section{g. Data processing and management}

The collected data was checked manually for completeness, coded and entered in to SPSS Version 22. After the entry was completed, data cleaning was performed by running frequency of each variable to check accuracy, inconsistency and missed value of the data.

\section{h. Data analysis}

Analysis was done using SPSS version 22. Descriptive statistics was calculated using frequency and percentage. All Variables having $\mathrm{p}$ value $<0.25$ in the bivariate analysis was fitted in to the multivariable logistic regression. Variables having p-value less than 0.05 in the multivariable binary logistic regression model were declared as significantly associated with the dependent variable. Finally, findings of the study were presented by using texts, tables and figures.

\section{Results}

\section{a. Socio-demographic respondents' parents}

characteristic

of

In this study, a total of 582 respondents were included with $100 \%$ response rate. Four hundred forty nine $(77.1 \%)$ participants' parents were married. About 517(88.8\%) of the respondents' parents' religion were Orthodox and 41(7\%) were Muslim. Two hundred sixty participants' fathers $(44.7 \%)$ and $214(36.8 \%)$ participants' mothers were able to Read and write. Concerning family size, $517(88.8 \%)$ of youth females had greater or equal to four families in their house. Regarding to estimated monthly income of youth females parents', almost half of respondents (272(46.7\%)) earned from 2001-3500birr per month. With regard to the participants job status, most respondents' $336(57.7 \%)$ were farmers and $82(14.1 \%)$ were governmental workers (Table 1).

Table I Socio-demographic characteristics of youth females' parent's in debrebirehan town, north shewa, Ethiopia2017 ( $N=582)$

\begin{tabular}{llll}
\hline Variables & Category & Frequency & Percent \\
\hline $\begin{array}{l}\text { Parent's Marital } \\
\text { status }\end{array}$ & Married & 449 & -77.1 \\
& Divorced & 79 & -13.6 \\
& Widowed & 54 & -9.3 \\
Parents Religion & Orthodox & 517 & -88.8 \\
& Muslim & 41 & -7 \\
& Protestant & 18 & -3.1 \\
& Catholic & 6 & -1 \\
Educational status & Illiterate & 115 & -19.8 \\
of father & Read \&write & 260 & -44.7 \\
& Elementary & 88 & -15.1 \\
& Secondary & 45 & -7.7 \\
& College and above & 74 & -12.7 \\
& Illiterate & 222 & -38.1 \\
Educational status \\
of mother & Read and write & 214 & -36.8 \\
& Elementary & 79 & -13.6 \\
& Junior/Secondary & 35 & -6 \\
& College and above & 32 & -5.5 \\
\hline
\end{tabular}




\begin{tabular}{llll} 
Table continued & & & \\
\hline Variables & Category & Frequency & Percent \\
\hline Family size in & $<=3$ & 65 & -11.2 \\
house & $>=4$ & 517 & -88.8 \\
Monthly income & $<=2000$ & 118 & -20.3 \\
& $2001-3500$ & 272 & -46.7 \\
& $>=3501$ & 192 & -33 \\
Parents' & Farmer & 336 & -57.7 \\
occupation & Merchant & 77 & -13.2 \\
& Gov'tal worker & 82 & -14.1 \\
& Private employee & 50 & -8.6 \\
& Daily wages & 37 & -6.4 \\
\hline
\end{tabular}

\section{b. Socio-demographic characteristics of youth females}

The mean age of youth females was $19.14+2.679$ years and most of participants' age group (58.1\%) was 15-19 years. Most of the youth females $517(88.8 \%)$ had single marital status. According to this study, about $521(89.5 \%)$ and 522(89.7 \%) participants were Orthodox and Amhara correspondingly. The educational status of youth females revealed that, $216(37.1 \%)$ and 208(35.7\%) were have College and above and secondary educational status respectively. Four hundred forty one (75.8\%) of the participants' house had radio and 271(46.6\%) of the participants house had television in their home. Regarding social media, 196 (33.7\%) of the youth females used face book. Two hundred thirty nine $(41.1 \%)$ of respondents lived with Parents and $393(67.5 \%)$ of the respondents' job was Schooling/student. Majority of the youth females $(60.5 \%)$ took training on gender issues (Table 2).

Table 2 Socio-demographic characteristics of youth females in debrebirehan town, north shewa, Ethiopia, June2017 ( $N=582)$

\begin{tabular}{|c|c|c|c|c|}
\hline \multirow[t]{2}{*}{ Variables } & \multirow[t]{2}{*}{ Categories } & \multirow[t]{2}{*}{ Frequency (\%) } & \multicolumn{2}{|c|}{$\begin{array}{l}\text { Awareness of sexua } \\
\text { trafficking }\end{array}$} \\
\hline & & & Yes & No \\
\hline \multirow[t]{2}{*}{ Age } & $15-19$ & $338(58.1)$ & 159 & 179 \\
\hline & $20-24$ & $244(41.9)$ & $14 \mid$ & 103 \\
\hline \multirow[t]{2}{*}{ Marital status } & Single & $517(88.8)$ & 265 & 252 \\
\hline & Married & $65(I I .2)$ & 35 & 30 \\
\hline \multirow[t]{4}{*}{ Religion } & Orthodox & $521(89.5)$ & 259 & 262 \\
\hline & Muslim & $42(7.2)$ & 33 & 9 \\
\hline & Protestant & $19(2.1)$ & 7 & 12 \\
\hline & Catholic & $7(1.2)$ & I & 6 \\
\hline \multirow[t]{4}{*}{ Ethnic group } & Amhara & $522(89.7)$ & 263 & 259 \\
\hline & Oromo & $3 I(5.3)$ & 16 & 15 \\
\hline & Tigary & $9(1.5)$ & 2 & 7 \\
\hline & Guragie & $20(3.4)$ & 14 & 6 \\
\hline \multirow[t]{5}{*}{ Education status } & Illiterate & $9(1.5)$ & 6 & 3 \\
\hline & Read \& write & $35(6.0)$ & 7 & 28 \\
\hline & Elementary & $114(19.6)$ & 52 & 62 \\
\hline & Secondary & $208(35.7)$ & 109 & 99 \\
\hline & College and above & $216(37.1)$ & 126 & 90 \\
\hline \multirow[t]{2}{*}{ Presence of radio at home } & Yes & $44 \mid(75.8)$ & 227 & 214 \\
\hline & No & $|4|(24.2)$ & 73 & 68 \\
\hline \multirow[t]{2}{*}{ Presence of Television at home } & Yes & $27 I(46.6)$ & 172 & 99 \\
\hline & No & $311(53.4)$ & 128 & 183 \\
\hline \multirow[t]{2}{*}{ Using social media like, face book } & Yes & $196(33.7)$ & 129 & 67 \\
\hline & No & $386(66.3)$ & $|7|$ & 215 \\
\hline \multirow[t]{5}{*}{ With whom are you living now } & Parents & $239(4 I .1)$ & 130 & 109 \\
\hline & Boyfriend/fiancé/husband & $96(16.5)$ & 50 & 46 \\
\hline & Mother & $37(6.4)$ & 24 & 13 \\
\hline & Father & $\mathrm{II}(\mathrm{I} .9)$ & 6 & 5 \\
\hline & Step parents & $6(1.0)$ & 3 & 3 \\
\hline
\end{tabular}




\begin{tabular}{|c|c|c|c|c|}
\hline \multirow[t]{2}{*}{ Variables } & \multirow[t]{2}{*}{ Categories } & \multirow[t]{2}{*}{ Frequency (\%) } & \multicolumn{2}{|c|}{$\begin{array}{l}\text { Awareness of sexua } \\
\text { trafficking }\end{array}$} \\
\hline & & & Yes & No \\
\hline & Relatives & $69(11.9)$ & 26 & 43 \\
\hline & Alone & $124(2 \mid .3)$ & 61 & 63 \\
\hline \multirow[t]{6}{*}{ Current job of the respondents } & Doing nothing/Jobless & $47(8.1)$ & 25 & 22 \\
\hline & Schooling/student & $393(67.5)$ & 207 & 186 \\
\hline & Trading & $37(6.4)$ & 22 & 15 \\
\hline & Hair dressing & $21(3.6)$ & 9 & 12 \\
\hline & Gov'tal worker & $21(3.6)$ & 16 & 5 \\
\hline & Daily wages & $63(10.8)$ & 21 & 42 \\
\hline \multirow[t]{2}{*}{ Taken education or training on gender issues } & Yes & $352(60.5)$ & 226 & 126 \\
\hline & No & $230(39.5)$ & 74 & 156 \\
\hline
\end{tabular}

\section{c. Awareness sexual trafficking among the youth} female

Regarding the source of information, about $56.6 \%$ and $56.0 \%$ of the youth females mentioned television, radio, respectively as sources of information. Brokers, friends and family were mentioned as mediators for sex trafficking by $85.5 \%, 30.5 \%$ and $14.9 \%$ of the youth females respectively. According to this study, about $70 \%$ of the respondents mentioned that they had heard of women being taken abroad for better work was become victim of sexual trafficking and 55.9\%, $53.7 \%$ and $21.9 \%$ of the respondents mentioned radio, television and friends respectively as sources of information for it. Concerning about the cause of sexual trafficking, $53.3 \%, 32.7 \%$ and $29.0 \%$ of youth females mentioned poverty, unemployment and hoping for a better life elsewhere respectively as reasons for being trafficked. Regarding the vulnerability age, about $56 \%$ of the participants reported that they did not know vulnerable age for sexual trafficking whereas about $24.3 \%$ of the participants reported that youth female's ages less than 25 years were vulnerable for sexual trafficking. About 72 (24\%) of the participants reported that they had been approached by someone else to assist them go abroad. One hundred eighty nine $(63 \%)$ of the respondents had good awareness of sexual trafficking (Table 3) of all youth females, about $300(52 \%)$ of respondents had awareness about sexual trafficking (Figure 2).

Table 3 Awareness sexual trafficking among youth females in debrebirehan town, north shewa, Ethiopia, June 20I7(N=300)

\begin{tabular}{|c|c|c|c|}
\hline Variables & Category & Frequency(582) & Percent \\
\hline \multirow[t]{5}{*}{$\begin{array}{l}\text { Source of information about sex } \\
\text { trafficking* }(n=300)\end{array}$} & Radio & 169 & $56.00 \%$ \\
\hline & Television & |7| & $56.60 \%$ \\
\hline & Friend & 67 & $22.20 \%$ \\
\hline & Relative & 24 & $7.90 \%$ \\
\hline & Others & 39 & $12.90 \%$ \\
\hline \multirow[t]{2}{*}{$\begin{array}{l}\text { Do you know about the mediator of } \\
\text { sexual trafficking }(n=300)\end{array}$} & Yes & 248 & 82.7 \\
\hline & No & 52 & 17.3 \\
\hline \multirow[t]{4}{*}{$\begin{array}{l}\text { Mediators for sexual } \\
\text { trafficking* }(n=300)\end{array}$} & Friends & 76 & $30.50 \%$ \\
\hline & Brokers & 213 & $85.50 \%$ \\
\hline & Family & 37 & $14.90 \%$ \\
\hline & Othersb & 19 & $7.60 \%$ \\
\hline $\begin{array}{l}\text { Have you heard of women being } \\
\text { taken abroad for better work } \\
\text { was become victim of sexual }\end{array}$ & Yes & 210 & $70 \%$ \\
\hline & No & 90 & $30 \%$ \\
\hline \multirow{2}{*}{$\begin{array}{l}\text { Source of information forgoing to } \\
\text { abroad become victim of Sexual } \\
\text { trafficking* }(n=300)\end{array}$} & Radio & $|5|$ & $55.90 \%$ \\
\hline & Television & 145 & $53.70 \%$ \\
\hline
\end{tabular}




\begin{tabular}{|c|c|c|c|}
\hline Variables & Category & Frequency(582) & Percent \\
\hline & Family & 21 & $7.80 \%$ \\
\hline & Relative & 23 & $8.50 \%$ \\
\hline & Friend & 59 & $21.90 \%$ \\
\hline & Othersc & 58 & $21.50 \%$ \\
\hline \multirow[t]{5}{*}{$\begin{array}{l}\text { Perceived reasons for sexually } \\
\text { trafficked } *(n=300)\end{array}$} & Poverty & 160 & $53.30 \%$ \\
\hline & Unemployment & 98 & $32.70 \%$ \\
\hline & Hope for better life elsewhere & 88 & $29.00 \%$ \\
\hline & Illiteracy & 22 & $7.30 \%$ \\
\hline & Low social status & 16 & $5.30 \%$ \\
\hline \multirow{2}{*}{$\begin{array}{l}\text { Do you know that there are people } \\
\text { send women for better work to } \\
\text { abroad to get money }(n=300)\end{array}$} & Yes & 178 & 59.3 \\
\hline & No & 122 & 40.7 \\
\hline \multirow[t]{4}{*}{$\begin{array}{l}\text { Which age groups are most likely to } \\
\text { be trafficked }(n=300)\end{array}$} & Age under 25 years old & 73 & 24.3 \\
\hline & Age more than 25 years old & 23 & $7.70 \%$ \\
\hline & Female of any age & 36 & $12 \%$ \\
\hline & I don't know & 168 & $56 \%$ \\
\hline \multirow{2}{*}{$\begin{array}{l}\text { Has anybody approached you to } \\
\text { assist you in going in other area or } \\
\text { abroad }(n=300)\end{array}$} & Yes & 72 & $24 \%$ \\
\hline & No & 228 & $76 \%$ \\
\hline \multirow[t]{2}{*}{ Level of sexual trafficking awareness } & $\begin{array}{l}\text { Poor awareness of sexual } \\
\text { trafficking }\end{array}$ & 111 & 37 \\
\hline & $\begin{array}{l}\text { Good awareness of sexual } \\
\text { trafficking }\end{array}$ & 189 & 63 \\
\hline
\end{tabular}

*Multiple responses are there, a NGO's written materials, mini medial, newspaper; b news paper, internet; $C$ newspaper, face book, mini media

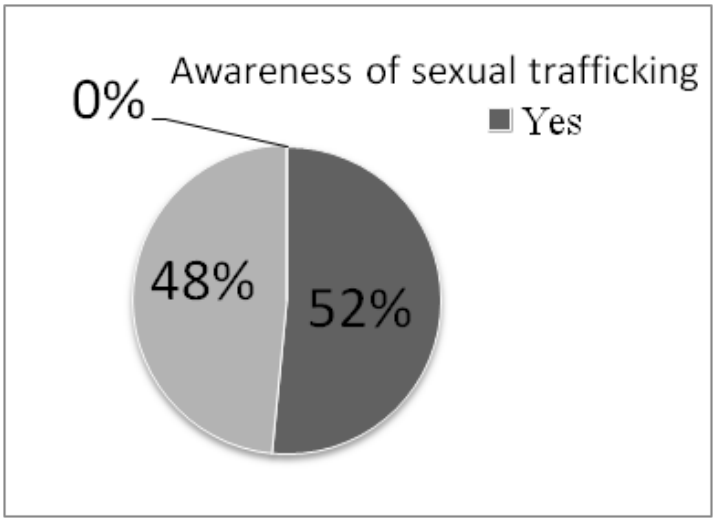

Figure 2 Awareness of sexual trafficking among youth females in debre birhan town, north shewa, Ethiopia 2017.

\section{d. Factors associated with awareness of sexual trafficking}

In bi variate logistic regression analysis, parent's religion, father's education, Mother's education, Parent's occupation, participant's age, Participant's education, having television at home, using social media like, face book, current job of the respondents and getting training on gender issues were significantly associated with awareness of sexual trafficking. However, in multivariable binary logistic regression analysis, mothers' education status, parents' occupation, current jobs of participant, having television in home and have taking training on gender issues were significantly associated with awareness of sexual trafficking with a p-value $<0.05$. According to this study, youth females whose parents' education status was elementary and secondary were 2.068(AOR=2.068, 95\% CI: $1.079-3.963)$ and 3.446(AOR=3.446, 95\% CI: $1.298-9.154)$ times more likely to be aware about sexual trafficking respectively compared to those youth females whose parents' education status was illiterate.

Youth females whose parents' occupation was Governmental workers were about $2.2(\mathrm{AOR}=2.2,95 \% \mathrm{CI}$ : 1.02-4.747) times more likely to be aware about sexual trafficking compared to those youth females whose parents' occupation was farming. Youth females who had governmental work were about 6.203(AOR $=6.203,95 \%$ CI: 1.099-35.005) times more likely to be aware about sexual trafficking compared to those youth females were jobless.

Based on this study, youth females who had television at home were about 2.083 (AOR=2.083, 95\% CI: 1.305-3.326) times more likely to be aware about sexual trafficking compared to their counterparts. Youth trained on gender issues were $3.887(\mathrm{AOR}=3.887,95 \% \mathrm{CI}$ : 2.591-5.832) times more likely to be aware about sexual trafficking compared to those youth females who did not take the training (Table 4). 
Table 4 Factors associated with awareness of sexual trafficking, June 2017( $N=582)$

\begin{tabular}{|c|c|c|c|c|c|c|}
\hline \multicolumn{7}{|c|}{ Awareness of sexual trafficking } \\
\hline Variables & Category & Total & Yes & No & COR (95\% C) & AOR(95\% C) \\
\hline \multirow[t]{5}{*}{ Parents Religion } & Orthodox & 517 & 257 & 260 & I & I \\
\hline & Muslim & $4 I$ & 34 & 7 & $44.9 \mid 4(|.| 39-|| .28)^{*}$ & $3.57(0.403-9.083)$ \\
\hline & Protestant & 18 & 8 & 10 & $.809(0.3 \mid 4-2.083)$ & $0.395(0.128-1.213)$ \\
\hline & Catholic & 6 & I & 5 & $.202(0.023-1.744)$ & $0.09 I(0.008-I .04 I)$ \\
\hline & Illiterate & 115 & 55 & 60 & I & I \\
\hline \multirow[t]{4}{*}{ Educational status of father } & Read \&write & 260 & 123 & 137 & $0.979(0.63|-| .52)$ & $0.798(0.435-1.464)$ \\
\hline & Elementary & 88 & 42 & 46 & $0.996(0.57 \mid-1.736)$ & $0.457(0.199-1.048)$ \\
\hline & Secondary & 45 & 28 & 17 & $1.797(0.888-3.636)$ & $0.737(0.26 \mathrm{I}-2.077)$ \\
\hline & College\& above & 74 & 52 & 22 & $2.579(1.389-4.785)^{*}$ & $0.330(0.103-1.060)$ \\
\hline \multirow[t]{5}{*}{$\begin{array}{l}\text { Educational status of } \\
\text { mother }\end{array}$} & Illiterate & 222 & 98 & 124 & I & I \\
\hline & Read \& write & 214 & 100 & 114 & I.II(.76I-I.6I8) & $0.998(0.645-I .546)$ \\
\hline & Elementary & 79 & 52 & 27 & $2.437(1.427-4.161)^{*}$ & $2.068(1.079-3.963)^{* *}$ \\
\hline & Secondary & 35 & 26 & 9 & $3.655(1.638-8.159)^{*}$ & $3.446(1.298-9.154)^{* *}$ \\
\hline & College\& above & 32 & 24 & 8 & $3.796(1.634-8.818)^{*}$ & $1.800(0.622-5.215)$ \\
\hline \multirow[t]{5}{*}{ Parents' occupation } & Farmer & 336 & 151 & 185 & I & I \\
\hline & Merchant & 77 & 42 & 35 & I.47(0.894-2.4I8) & $0.626(0.322-1.215)$ \\
\hline & Gov'tal worker & 82 & 64 & 18 & $4.356(2.475-7.667)^{*}$ & $2.2(1.020-4.747) * *$ \\
\hline & Private worker & 50 & 24 & 26 & I.I 3 I(0.624-2.05) & $0.788(0.380-1.635)$ \\
\hline & Daily wages & 37 & 19 & 18 & $1.293(0.655-2.552)$ & $0.863(0.38 I-I .95 I)$ \\
\hline \multirow[t]{2}{*}{ Age } & $15-19$ & 338 & 159 & 179 & I & I \\
\hline & $20-24$ & 244 & $14 \mid$ & 103 & $1.54 \mathrm{I}(\mathrm{I} .106-2.15)^{*}$ & $1.560(0.993-2.45 \mathrm{I})$ \\
\hline \multirow[t]{5}{*}{$\begin{array}{l}\text { Educational status of } \\
\text { participant }\end{array}$} & Illiterate & 9 & 6 & 3 & I & I \\
\hline & Read \& write & 35 & 7 & 28 & $0.125(0.025-0.628)$. & $5.019(0.992-25.382)$ \\
\hline & Elementary & 114 & 52 & 62 & $0.419(0.100-1.760)$ & $0.197(0.069-0.564)$ \\
\hline & Secondary & 208 & 109 & 99 & $0.55 I(0.134-2.260)$ & $0.911(0.507-1.637)$ \\
\hline & College\& above & 216 & 126 & 90 & $0.700(0.17 \mid-2.873)$ & $0.787(0.48|-| .285)$ \\
\hline \multirow[t]{2}{*}{$\begin{array}{l}\text { Presence of Television at } \\
\text { home }\end{array}$} & Yes & 271 & 172 & 99 & $2.484(\mathrm{I} .777-3.47)^{*}$ & $2.083(1.305-3.326)^{* *}$ \\
\hline & No & 311 & 128 & 183 & I & I \\
\hline \multirow[t]{2}{*}{$\begin{array}{l}\text { Using social media like, face } \\
\text { book }\end{array}$} & Yes & 196 & 129 & 67 & $2.42 \mathrm{I}(1.694-3.46)^{*}$ & $1.277(0.804-2.030)$ \\
\hline & No & 386 & 171 & 215 & I & I \\
\hline \multirow[t]{6}{*}{$\begin{array}{l}\text { Current job of the } \\
\text { respondents }\end{array}$} & Jobless & 47 & 25 & 22 & $2.273(1.046-4.94)^{*}$ & I.564(0.628-3.897) \\
\hline & Student & 393 & 207 & 186 & $2.226(1.27 \mid-3.897)^{*}$ & $1.498(0.736-3.050)$ \\
\hline & Trading & 37 & 22 & 25 & $2.933(1.267-6.79)^{*}$ & $1.703(0.630-4.603)$ \\
\hline & Hair dressing & 21 & 9 & 12 & $1.500(0.546-4.121)$ & $0.419(0.1 \mid 7-1.507)$ \\
\hline & Gov'tal worker & 21 & 16 & 5 & $8.667(2.224-33.78)^{*}$ & $6.203(1.099-35.005)^{* *}$ \\
\hline & Daily wages & 63 & 21 & 42 & I & I \\
\hline \multirow[t]{2}{*}{$\begin{array}{l}\text { Taking education or training } \\
\text { on gender issues. }\end{array}$} & Yes & 352 & 226 & 126 & $3.78 \mathrm{I}(2.659-5.377)^{*}$ & $3.887(2.59 \mid-5.832)^{* *}$ \\
\hline & No & 230 & 74 & 156 & I & I \\
\hline
\end{tabular}




\section{Discussion}

The study was aimed to assess awareness of sexual trafficking and associated factors among youth females. It was supposed that, this study provided important information and created overall image on Awareness of sex trafficking and associated factors among youth females in Debrebirhan town, North Shewa. In this study, $52 \%$ of respondents had awareness of sexual trafficking which was lower than studies conducted in Nepal, Nigeria and Ethiopia (Bahir Dar) showed that $76 \%, 86.1 \%$ and $60 \%$ of the respondents had awareness of sexual trafficking, respectively. ${ }^{26-28}$ Similarly, a cross sectional study conducted in Nigeria showed that $97.4 \%$ of the women reported that they had heard of women being taken abroad for commercial sex work..$^{29}$ This discrepancy may be due to the implementation of sexual trafficking prevention interventions, as well as cross-cultural variation. Regarding the source of information, the youth females stated television $(56.6 \%)$, radio $(56.0 \%)$ and friends $(22.2 \%)$ as sources of information in this study whereas in the Bahir Dar study the youth females mentioned television (64\%), friends (46\%) and radio $(37 \%)$ as sources of information. ${ }^{26}$ On the other hand, the study done in Nepal, $94.6 \%, 49.5 \%, 36 \%, 24.3 \%$, and $15.3 \%$ of the respondents mentioned media (i.e., radio or television), friends, family/relatives, schools and NGOs/health professionals as sources of information respectively. ${ }^{27}$ The possible reason might be due to the presence of difference source of information among different area.

Brokers and friends were mentioned as mediators for sex trafficking by $85.5 \%$ and $30.5 \%$ of the study participants; individually whereas in a study done in Bahir Dar friends and brokers were mentioned by $87 \%$ and $74 \%$ of the respondents, respectively as mediators for sex trafficking. ${ }^{26}$ Similarly, the study carried out in Nepal, relatives $(51.4 \%)$ and friends $(34.2 \%)$ were mentioned as mediators for sexual trafficking. ${ }^{27}$ The above findings were inconsistent with the studies done in Nigeria and South Africa. ${ }^{28,30}$ This might be due to the Knowledge difference about the mediators and existence of different mediators in different areas. Concerning about the cause of sexual trafficking, $53.3 \%, 32.7 \%$ and $29.0 \%$ of the youth females mentioned poverty, unemployment and hoping for a better life elsewhere, respectively as reasons for being trafficked. Similarly, the study done in Bahir Dar city, $45 \%, 50 \%$ and $72 \%$ of the study participants mentioned poverty, unemployment and hoping for a better life elsewhere, one by one as reasons for sex trafficking. ${ }^{26}$ These findings were not in line with those reported in studies from Nigeria, South Asia, and South Africa. ${ }^{28,31,32}$ On the other hand, the study done in Nepal showed that $62.2 \%$, $58.6 \%, 56.8 \%$, and $25.2 \%$ of the respondents mentioned poverty, lack of awareness, interest on big money, and illiteracy correspondingly as reasons for being trafficked. ${ }^{27}$ The possible explanation might be due to having knowledge difference on the causes of sexual trafficking and might be the presence of different causes in different countries.

Regarding to the vulnerability age group, about $24.3 \%$ of the participants reported that youth female's aged less than 25 years were vulnerable for sexual trafficking which was lower than the studies done in Nepal (48.6\%), Bahir Dar (71.4\%) and South Asia $(72 \%){ }^{27,26,31}$ The difference might be due to gap of knowledge on vulnerable age group for sexual trafficking among youth females. In this study, about $24 \%$ of youth females had been approached by someone to assist them to go abroad which was lower than the studies done in Bahir Dar town in Ethiopia (25\%) and Benin city in southern Nigeria $(31.9 \%) .^{26,29}$ This discrepancy may be due to the extent of the problem and sexual trafficking promotion activities. Based on this study, $352(60.5 \%)$ of the participants took training on gender issues.
The finding of this study was higher than the study done in Bahir Dar city in which about $29 \%$ of study participants had taken some training on gender issues. ${ }^{26}$ This might be due to the fact that the stake holders might be understands the issue of sexual trafficking and in turn, this might increase their intention to give training.

This study also revealed that youth females whose mothers' education status was elementary and secondary were about 2.068(AOR=2.068, 95\% CI: $1.079-3.963)$ and 3.446(AOR=3.446, 95\% CI: 1.298-9.154) times more likely to be aware about sexual trafficking respectively compared to those youth females whose parents' education status was illiterate. However, study done in Nepal showed that the educational status of mother was not associated with awareness of sexual trafficking. This might be due to the fact that educated mothers, simply due to their tied up life style, might not have intimate approach with their daughters which might in turn influence the awareness of their daughters' regarding about sexual trafficking. Regarding the parents' occupation, the study revealed that youth females whose parents' occupation was Governmental employment were about $2.2(\mathrm{AOR}=2.2,95 \% \mathrm{CI}: 1.02-4.747)$ times more likely to be aware about sexual trafficking compared to those youth females whose parents' occupation was farming. This finding was supported by the Nepal study (AOR=3.89,95\% CI:1.58-9.58). ${ }^{27}$ The reason might be due to the fact that governmental workers might have high access of social media and mass media than farmer as source of information for sexual trafficking. The reason might be due to the Government workers might have different life status and awareness about sexual trafficking from country to the country.

In this study, youth females who had governmental worker at current situation were about $6.203(\mathrm{AOR}=6.203$, 95\% CI: 1.099 35.005) times more likely to be aware about sexual trafficking compared to those youth females who had doing daily wages. This finding was not supported by the findings of Bahir Dar town study and Nepal study. ${ }^{26,27}$ The reason might be due to the fact that governmental workers might have high access of social media and mass media than farmer as source of information for sexual trafficking. This might be due to the fact that youth females might have different work from place to place and this might affect the awareness of youth females about sexual trafficking. According to this study, youth females who had television at home were about $2.083(\mathrm{AOR}=2.083,95 \% \mathrm{CI}$ : 1.305-3.326) times more likely to be aware about sexual trafficking compared to their counterparts. In line with this study, the study done in Bahir Dar town revealed that youth girls who had television at home were about 2.19(AOR=2. 19, 95\% CI: 1.31-3.67) times more likely to be aware about sexual trafficking compared to their counterparts. This study finding was also supported by the study done in Nepal (AOR=6.67, 95\% CI: 3.99-9.54). ${ }^{27}$ This might be due to the youth females were not watch television programs which relate to sexual trafficking. This might be due to using radio or television together as one variable rather than using separately for each radio and television in Nepal study.

Based on this study, youth females trained on gender issues were $3.887(\mathrm{AOR}=3.887,95 \% \mathrm{CI}: 2.591-5.832)$ times more likely to be aware about sexual trafficking compared to those youth females who did not take the training. This finding was aligned with the study done in Bahir Dar town (AOR=3. 59, 95\% CI: 2.11-6.10). ${ }^{26}$ This might be due to the fact that the stake holders might be understand the issue of sexual trafficking and in turn, this might increase their intention to give training. 


\section{Limitations}

a. The study design s cross-sectional. So, it has its drawback (this does not show which one is first effect or cause).

b. Because of the self-administered questionnaire, social desirability bias may have occurred to some degree.

c. There were shortages of literatures (studies) for discussion.

\section{Conclusions}

The awareness of youth females about sexual trafficking in this study was low (52\%). According this study, having a television at home, parents' education status, parents' occupation, current jobs of participant, and have taking training on gender issues were significantly associated with awareness of sex trafficking. Therefore, providing education about sexual trafficking will help to increase sexual trafficking awareness among youth females.

\section{Declarations}

\section{Ethics approval and consent to participant}

Ethical clearance was obtained from Mekelle University College of health science, ethical review board and permission got from Debre Birhan town administrative office and administrative of selected kebeles. The research proposal evaluated and approved by the Research Ethics Review Committee [HRERC 0910/2017] of College of Health Sciences, Mekelle University and ethical clearance gained. Official cooperation and permission found from Debre Birhan town administrative office and selected Kebele administrative office. Moreover, prior to commencing the study, a written informed consent took from each respondent before data collection. Informed consent found from a respondent whose age is equal and greater than 18 . Assent consent given by parents for ageless 18 youth young women. Confidentiality kept by omitting their name and personal identification of participant no compelled to the study.

\section{Acknowledgments}

None

\section{Conflicts of interest}

The author declares that there are no conflicts of interest.

\section{References}

1. United Nations Office of Drugs and Crime. Protocol to prevent, suppress and punish trafficking in persons, especially women and children, supplementing the United Nations Convention against Transnational Organized Crime. 2000

2. Neha A Deshpande, Nour NM. Sex Trafficking of Women and Girls. Rev Obstet Gynecol.2013;6(1):e22-e27.

3. https://www.unodc.org/unodc/en/human-trafficking/global-report-ontrafficking-in-persons.html

4. International Organization for Migration (IOM): Assessment of Trafficking in Women and Children in and from Ethiopia. Addis Ababa, Ethiopia: IOM 2010.

5. Konstantopoulos WM, Ahn R, Alpert EJ. An international comparative public health analysis of sex trafficking of women and girls in eight cities: achieving a more effective health sector response. J Urban Health. 2013;90(6):1194-1204.
6. International Labour Organization (ILO): ILO Global Estimate of Forced Labour 2012: Results and Methodology. Geneva: International Labour Organization; 2012.

7. United Nations Crime and Justice Information network (UNCIJIN), Annual Report on human trafficking crimes. 2010.

8. UNICEF. Trafficking in human beings especially women and children in Africa. $2^{\text {nd }}$ edn. Italy: UNICEF Innocent Research centre Florence; 2005.

9. Tom Gardner. Ethiopian women face new threat of human trafficking as economic gains slow to trickle down. 2016

10. https://2009-2017.state.gov/j/drl/rls/hrrpt/2013humanrightsreport/ index.htm\#wrapper

11. International Labour Organization (ILO). Trafficking in persons overseas for labour purposes the case of Ethiopian domestic workers. Addis Ababa, Ethiopia: ILO country office. 2011.

12. United State Department of State, Trafficking in persons Report Ethiopia: 2012.

13. International Labour Organization(ILO). Trafficking in persons overseas for labour purposes:The case of Ethiopian domestic workers. ILO country office. Addis Ababa,Ethiopia:2013.

14. Zimmerman C, Hossain M, Watts C. Human trafficking and health: a conceptual model to inform policy, intervention and research. Soc Sci Med. 2011;73(2):327-335.

15. Hossain M, Zimmerman C, Abas M, et al. The relationship of trauma to mental disorders among trafficked and sexually exploited girls and women. Am J Public Health. 2010;100(12):2442-2449.

16. Ostrovschi N, Prince MJ, Zimmerman C, et al. Women in post-trafficking services in Moldova: diagnostic interviews to assess common mental disorders over two time periods among returning women. BMC Public Health. 2011;11:232.

17. Abas M, Ostrovschi NV, Prince M, et al. Risk factors for mental disorders in women survivors of human trafficking: a historical cohort study. BMC Psychiatry. 2013;13:204.

18. Silverman JG, Decker MR, Gupta J, et al. Syphilis and hepatitis B Coinfection among HIV-infected, sex-trafficked women and girls. Nepal Emerg Infect Dis. 2008;14(6):932-934.

19. Barrows Jeffrey, Finger Reginald. Human Trafficking and the Healthcare Professional. South Med J. 2008;101:521-524.

20. https://www.ecoi.net/en/document/219987

21. Beydoun, Khaled. The Trafficking of Ethiopian Domestic Workers into Lebanon: Navigating through a Novel Passage of the International Maid Trade. Berkeley Journal of International Law. 2006; 24(3):1009-1045.

22. Mesfin D. The Challenges and prospects of female labour migration to the Arab Middle East: A Case study of women returnees in the town of Girana, North Wollo, Ethiopia. 2011

23. Asefach Haileselassie. An Investigation in to the experiences of Female victims of Trafficking in Ethiopia. University of South Africa: Cape Town, South Africa. 2012.

24. Elias Ashine. Trafficking of Ethiopian women and girls to the Middle East. Hungary:Central European university. 2013.

25. Azage M, Abeje G, Mekonnen A. Sex trafficking awareness and associated factors among youth females in Bahir Dar town, North-West Ethiopia: a community based study. BMC women's health. 2014;14:85.

26. Shrestha R, Karki P, Suwal A, et al. Sex Trafficking Related Knowledge, Awareness, and Attitudes among Adolescent Female Students in Nepal: A Cross-Sectional Study. PLoS One. 2015;10(7): e0133508. 
27. Omorodion FI. Vulnerability of Nigerian secondary school to human sex trafficking in Nigeria. Afr J Reprod Health. 2009;13(2):33-48.

28. Okonofua FE, Ogbomwan SM, Alutu AN, et al. Knowledge, attitudes and experiences of sex trafficking by young women in Benin City, South Nigeria. Soc Sci Med. 2004;59(6):1315-1327.

29. Woolman S, Bishop M. State as pimp:sexual slavery in South Africa Dev South Afr. 2006;23(3):385-400.
30. Huda S. Sex trafficking in South Asia. International Journal of Gynecology and Obstetrics. 2006;94: 374-381.

31. Ghimire D. Editor Prevention, Care, Rehabilitation and Reintegration of Rescued Girls: ABC's Experience. Technical Consultative Meeting on Anti-trafficking Programmes in South Asia. 2001.

32. Utility Service Provision fromPlanning Perspective(The case of Debre BirhanTown, ANRS, Ethiopia: 2016. 